\title{
Introduction to Part II
}

\section{Thom Davies}

Pollution surrounds us all. From the clothes we wear, to the way we travel, to our consumption choices, we are all - in highly uneven ways - creators and repositories of environmental damage. Toxicants have become increasingly ubiquitous in everyday life, and toxic potential suspends itself between absolute mundanity and perpetual threat. Yet despite the ever-present realities of contamination and environmental damage, pollution is often very difficult to sense or witness. Hazardous substances, for example, are often impossible to observe with the naked eye. According to the dominant narrative (see Kuchinskaya 2014), the dangers of chemical spills, radioactive particles, and air pollution, for example, would all be rendered imperceptible without the intervention of scientific devices; chemical sensors, Geiger counters, air meters, and so on. The human body alone, it seems, is not equipped to grapple with the agencies of late-modern discard. But what is it about pollution that gives it this uncanny characteristic? And moreover, does this narrative of sensorial ignorance correspond with the actually existing experience of living with pollution?

Toxic pollution is occluded from our senses in two primary ways: through scale and through temporality. Geographically, the impacts of toxic things can transcend the widest of scales: from the sphere of microbiology - operating at the cellular level within the borders of the polluted body - to a global reach, where toxic pollution spreads invisibly, ignoring geopolitical boundaries in the land, sea, and air. From the impacts of nuclear disasters to the spread of 
microplastic pollution, the silent mobility of pollution is no respecter of national borders, state lines, or passport control. At the scale of the individual, pollution can render human and more-than-human bodies "open," exposing the permeability of skin, tissue, and bone. Put simply, pollution is often too tiny or too vast to be fully comprehended. Scale and distance can conspire to make pollution enigmatic from a human perspective.

Thinking beyond space, time can make pollution unknowable in other ways, too. Temporally, environmental hazards may linger and accumulate as toxic lag, taking generations to make an impact, and allowing past pollution to transfer its harmful presence to the future (Nixon 2011; Murphy 2015; Boudia et al. 2018; Davies 2018). The gradual velocity of pollution creates a temporal blind spot, drip-feeding its toxic violence across the distance of months, years, or even lifetimes. Time obscures the possibility of knowing, for example, if a particular substance from the past has caused a particular cancer today. It conceals the impacts of our environmental decisions from those who are destined to inherit our pollution in the future. Time hides pollution from plain view, making it difficult to sense or make sense of. In the most extreme cases, the impacts of toxic pollution will only reveal themselves years later, in the illnesses and deaths of those who are exposed (Davies 2019). Even then, it takes political work - often by environmental justice activists - to transform a sick body into a political fact (Armiero and Fava 2016). In some polluted communities, the only witnesses to years of environmental damage can be found in fenceline stories of mysterious sickness and lost relatives, with the graveyard becoming a reluctant archive of contested and occluded exposure.

And herein lies the problem: How can individuals, when faced with the peculiar opacity of pollution, bear witness to its impacts? Which senses do we rely upon when we are confronted by toxic hazards? Moreover, which perspectives and epistemologies are silenced in environmental justice struggles, and how might we broaden our framework of creating toxic truths? These questions are put into sharp relief in an age of post-truth, where expertise of all kinds is being diminished, undermined, and questioned. In this section - drawing on case studies from Ecuador, Ghana, and Brazil - the authors take up the challenge of how to make "sense" of pollution and witness its impacts, by looking at different ways that pollution is being voiced and observed by the public.

But how can you witness pollution if it is invisible? As we saw in the previous chapter, where we encountered the cesspits and pig shit of North Carolina's hog industry, not all pollution is unsenuous. As countless frontline communities around the world testify, pollution can also be embodied, viscous, acrid, and uncanny. It can stick in the back of your throat and cling to your nostrils. It can bring you out in rashes or leave you short of breath. For those living in 
highly toxic geographies, such as Louisiana's "Cancer Alley," pollution can also catch you off-guard and wake you up in the middle of the night (Davies 2018). Pollution can also be witnessed in the hospital records of fenceline communities, and in the memories of those who have survived toxic accidents, such as Bhopal, Chernobyl, and Fukushima. But it can also be witnessed in mundane ways: as anyone who has visited any coastline on this planet in the last few decades can testify, pollution can be found in the waves lapping against the shore, in the form of unruly plastic flotsam.

In a world beset by an increasing toxic presence, perhaps the invisibility of pollution has been overplayed within discard studies (Peeples 2011; Kuchinskaya 2014). Instead of focusing our attention solely on the invisibility of technological hazards - which has dominated environmental thought for some time - we should extend our attention to the myriad ways that individuals do notice, sense, and witness the circulation and accumulation of pollution (Balayannis 2019; Davies 2019). The era of post-truth has made us more attentive to the importance of stories, narratives, and emotions within political struggles. Paradoxically - and in line with the idea of progressive populism (Bosworth 2019) - this may offer new opportunities to take the knowledge claims of local communities much more seriously. By refocusing our attention on the body as an environmental sensor, for example, a new wave of academic research has sought to understand pollution via the experiences of those who actually live with it. Recent environmental justice scholarship has highlighted the importance of "slow observations" (Davies 2018), "bodily reasoning" (Shapiro 2015), and "resigned activism" (Lora-Wainwright 2017) as key modes of understanding pollution that may otherwise be dismissed or overlooked. These approaches do not fit neatly into definitions of "citizen science," but they do display an expertise about pollution that demands to be taken seriously.

In this part of the book, the authors bring to task the assumption that pollution is non-sensory. In the chapter by Amelia Fiske, we will see how a touching toxicity plays an important role in making pollution tangible for lawyers, activists, and tourists who go on toxic tours in the Ecuadorian rainforest. Fiske focuses on the role of a simple auger - a tool for removing a small core of soil from contaminated ground - highlighting how witnessing the sticky materiality of oil extraction can bring questions of injustice to the surface. By inviting participants to touch the toxic sludge, and smell its acrid notes, it becomes impossible to ignore the reality that certain people are exposed to the burden of pollution in the name of capitalist profit. During the toxic tours, the dirty "stink and stickiness" of oil becomes both the message and the medium for seeking environmental justice. Using the auger to collect samples of contaminated soil, Fiske explains, mimics the scientific practices of formal experts - but instead of 
creating "data" about pollution, it creates a story, exposing environmental injustice as viscous, fetid, and unmissibly there.

The challenge of making pollution present is also taken up by Peter C. Little and Marina Da Silva, who both focus on visual dimensions of pollution. Little takes us to one of the world's largest e-waste dumps, in Agbogbloshie, a district in Accra, the capital of Ghana. He explores how workers who recycle e-waste in this vibrant urban market are able to make their injuries and toxic working conditions visible by sharing digital photographs. Little describes how his participatory visual methods allowed his participants to show a side of Agbogbloshie not often witnessed by outsider photographers, who often represent e-waste extraction through the predictable prism of misery and spectacle. In the next chapter, Da Silva discusses the issue of visuality in a different way through the notion of "visual pollution." In her exploration of the world's first "clean city law" (Lei Cidade Limpa) in São Paulo, Brazil, she reveals how the antigraffiti and anti-advertisement law has been interpreted and manipulated by regressive urban governors. Situated within the anti-environment populism of President Bolsonaro, Da Silva demonstrates how - in line with other types of contamination - what counts as visual pollution is a highly political decision.

Together, the chapters in this section of Toxic Truths provide a useful counterbalance to imaginations of pollution as "invisible" without the aid of scientific knowledge and devices. They push back against the tendency to frame discussions of pollution from the starting point of sensorial ignorance and move away from reducing local knowledge to narrow data entry points in citizen science projects. Rather, here we will read about how living with pollution can be a highly sensed, witnessed, and embodied experience.

\section{References}

Armiero, M. and Fava, A. 2016. Of humans, sheep, and dioxin: A history of contamination and transformation in Acerra, Italy. Capitalism Nature Socialism, 27(2), 67-82.

Balayannis, A. 2019. Toxic sights: The spectacle of hazardous waste removal. Environment and Planning D; Society and Space, 1-19.

Bosworth, K. 2019. The people know best: Situating the counterexpertise of populist pipeline opposition movements. Annals of the American Association of Geographers, 109(2), 581-592.

Boudia, S., Creager, A. N., Frickel, S., Henry, E., Jas, N., Reinhardt, C., and Roberts, J. 2018. Residues: Rethinking chemical environments. Engaging Science, Technology, and Society, Society for Social Studies of Science, 4, 165-178.

Davies, T. 2018. Toxic space and time: Slow violence, necropolitics, and petrochemical pollution. Annals of the American Association of Geographers, 108(6), 1537-1553. 
Davies, T. 2019. Slow violence and toxic geographies: "Out of sight" to whom? Environment and Planning C: Politics and Space. DOI: 10.1177/2399654419841063.

Kuchinskaya, O. 2014. The Politics of Invisibility: Public Knowledge about Radiation Health Effects after Chernobyl. New York: MIT Press.

Lora-Wainwright, A. 2017. Resigned Activism: Living with Pollution in Rural China. New York: MIT Press.

Murphy, M. 2015. Chemical infrastructures of the St Clair River. In N. Jas and S. Boudia S. (eds), Toxicants, Health and Regulation since 1945. London: Routledge, pp. 103-115.

Nixon, R. 2011. Slow Violence and the Environmentalism of the Poor. London: Harvard University Press.

Peeples, J. 2011. Toxic sublime: Imaging contaminated landscapes. Environmental Communication: A Journal of Nature and Culture, 5(4), 373-392.

Shapiro, N. 2015. Attuning to the chemosphere: Domestic formaldehyde, bodily reasoning, and the chemical sublime. Cultural Anthropology, 30(3), 368-393. 